\title{
HSPD1 is not a major susceptibility gene for rheumatoid arthritis in the French Caucasian population
}

\author{
Laurent Jacq · Vitor Hugo Teixeira · Sophie Garnier • Laëtitia Michou • \\ Philippe Dieudé · Dominique Rocha · Céline Pierlot · Isabelle Lemaire · \\ Patrick Quillet · Pascal Hilliquin · Hamdi Mbarek · Elisabeth Petit-Teixeira • \\ François Cornélis
}

Received: 9 July 2007/ Accepted: 18 September 2007/Published online: 11 October 2007

(C) The Japan Society of Human Genetics and Springer 2007

\begin{abstract}
The heat shock $60-\mathrm{kDa}$ protein 1 (HSP60) is involved in immune and inflammatory reactions, which are hallmarks of rheumatoid arthritis (RA). HSP60 is encoded by the HSPD1 gene located on 2q33, one of the suggested RA susceptibility loci in the French Caucasian population. Our aim was to test whether HSPDI is a major susceptibility gene by studing families from the French Caucasian population. Three single nucleotide polymorphisms (SNPs) were studied in $100 \mathrm{RA}$ trio families, and 100 other families were used for replication. Genetic analyses were performed by comparing allelic frequencies, by applying the transmission disequilibrium test, and by assessing the genotype relative risk. We observed a significant RA association for the $C / C$ genotype of rs 2340690 in the first sample. However, this association was not confirmed when the second sample was added. The two other SNPs and the
\end{abstract}

L. Jacq $(\bowtie) \cdot$ V. H. Teixeira · S. Garnier · L. Michou .

P. Dieudé - D. Rocha - C. Pierlot - I. Lemaire - P. Quillet .

H. Mbarek - E. Petit-Teixeira · F. Cornélis

GenHotel-EA3886, Evry-Paris VII Universities,

2 rue Gaston Crémieux, 91057 Evry-Genopole cedex, France

e-mail: Laurent@polyarthrite.net

L. Jacq · I. Lemaire · P. Quillet · P. Hilliquin · F. Cornélis

Hôpital Sud Francilien, 59 bd Henri Dunant,

91100 Corbeil-Essonnes, France

V. H. Teixeira

Faculty of Medicine, University of Coimbra,

Coimbra, Portugal

P. Dieudé

Hôpital Bichat, AP-HP, 46 rue Henri Huchart,

75018 Paris, France

F. Cornélis

Hôpital Lariboisière, AP-HP, 2 rue Ambroise Paré,

75010 Paris, France haplotype analysis did not give any significant results. We conclude that $H S P D 1$ is not a major RA susceptibility gene in the French Caucasian population.

Keywords HSPDI - Rheumatoid arthritis · Candidate gene $\cdot$ Heat shock protein $\cdot$ Chaperonin

\section{Introduction}

Rheumatoid arthritis (RA) is a common human systemic autoimmune disease, for which previous studies have suggested the importance of genetic factors (Seldin et al. 1999). Two susceptibility genes have been established so far (and are confirmed by the results from the sample sets of the present study), HLA-DRB1 and PTPN22, which account for 19 and $1 \%$ of the familial aggregation respectively (Tezenas du Montcel et al. 2005; Michou et al. 2007). A genome scan suggested 19 non-HLA susceptibility loci in a French Caucasian population (Osorio et al. 2004). HSPD1 is located in one of these regions (2q33), and encodes for a member of the chaperonin family (heat shock $60-\mathrm{kDa}$ protein 1, HSP60). Heat shock proteins constitute a family of proteins involved in cell homeostasis, immune and inflammatory reactions. They can regulate gene expression, cell proliferation, and death. HSP60 is a mitochondrial chaperonin, highly preserved during evolution, and responsible for protein folding (Cappello et al. 2004). Homozygous Drosophila melanogaster HSPDI homolog - - mutants die early on during embryogenesis (Perezgasga et al. 1999). In human cells, knockdown of the HSPD1 gene compromises the folding of the mitochondrial matrix enzymes, indicating that HSP60 plays an essential role (Corydon et al. 2005). Furthermore, HSP60 can downregulate adaptive immune responses and is involved 
in apoptosis in patients with systemic autoimmune diseases (Zanin-Zhorov et al. 2006; Jamin et al. 2005). Interestingly, DNA vaccination with the HSPDI gene can inhibit adjuvant arthritis in Lewis rats (Quintana et al. 2003).

HSPD1 is thus a positional and functional RA candidate gene. The aim of this study was to test whether HSPD1 is a major susceptibility gene by analyzing families from the French Caucasian population.

\section{Material and methods}

Rheumatoid arthritis families were recruited through a media campaign, and then individuals who fulfilled the 1987 American College of Rheumatology criteria were selected (Arnett et al. 1988). All subjects provided informed consent, and an ethics committee (KremlinBicêtre, France) approved the study. The two samples included DNA from 100 unrelated French Caucasian trio families (a patient and both parents) along with four grandparents of French Caucasian origin (Table 1).

DNA was isolated and purified from whole blood according to standard protocols (Sambrook et al. 1989). The single nucleotide polymorphisms (SNPs) were selected with a required minor allele frequency of $>18 \%$ among the European Caucasian population and $r^{2}>0.8$ using the QuickSNP web server (http://bioinformoodics.jhmi.edu/ quickSNP.pl).

\section{Genotyping}

Genotyping of rs 2340690 was performed by polymerase chain reaction followed by the restriction fragment length polymorphism method (Botstein et al. 1980). The designed primers are available on request. The resulting 434-bp fragment was digested with $A l u \mathrm{I}$, generating three

Table 1 Characteristics of the rheumatoid arthritis index cases

\begin{tabular}{lll}
\hline & $\begin{array}{l}\text { Sample 1 } \\
(n=100)\end{array}$ & $\begin{array}{l}\text { Sample 2 } \\
(n=100)\end{array}$ \\
\hline Females $(\%)$ & 87 & 90 \\
Mean age at disease onset (years) & $32( \pm 10)$ & $31( \pm 6)$ \\
Mean disease duration (years) & $18( \pm 7)$ & $16( \pm 8)$ \\
Patients with bone erosion (\%) & 90 & 79 \\
$\begin{array}{l}\text { Patients seropositive for } \\
\text { rheumatoid factor }(\%)\end{array}$ & 81 & 76 \\
$\begin{array}{l}\text { Patients carrying at least one } H L A-D R B 1 \\
\quad \text { shared epitope allele* }(\%)\end{array}$ & 78 & 80 \\
\hline
\end{tabular}

*DRB1*0101, DRB1*0102, DRB1*0401, DRB1*0404, DRB1*0405, $D R B 1 * 0408, D R B 1 * 1001$

$n$ is the number of cases fragments for the $C$ allele $(68,103,263 \mathrm{bp})$, and two for the $T$ allele $(103,331 \mathrm{bp}$, the $103 \mathrm{bp}$ being an internal control for restriction). Allelic discrimination assays (assay C 8744787 10, C 16261693 10; Applied Biosystems, Foster City, CA, USA) were used to genotype rs788016 and rs2605039, respectively, following the manufacturer's protocol. Genotypes were assessed blindly by two investigators (LJ-CP), and 10\% of the samples (chosen randomly) were regenotyped for quality control.

\section{Statistical analysis}

Hardy-Weinberg equilibrium (HWE) was checked for with virtual controls consisting of parental alleles untransmitted to RA index cases. Association and linkage were examined using three methods. Affected family-based controls (AFBAC) were used to compare transmitted and untransmitted allelic frequencies. The transmission disequilibrium test (TDT) was used to detect linkage through preferential transmission of one allele to the affected subjects. The genotype relative risk (GRR) was calculated to compare the genotypic distributions in patients and controls (Spielman et al. 1993; Thomson 1995; Lathrop 1983). Significance of the $P$ value was assessed at the $5 \%$ level, which led to a replication test in 100 other families (sample 2) if at least one test was significant. In case of a positive replication, 265 European Caucasian families were available.

\section{Power calculation}

Using the European population minor allele frequencies of 20, 43 and $25 \%$ for rs 2340690 , rs788016 and rs2605039, respectively, with a sample size of 100 patients and 100 controls, as previously described (Garnier et al. 2006), we had $80 \%$ power to detect an association $(P<0.05)$ when the difference in allelic frequencies between patients and controls was at least 10.7, 12.4 and $11.4 \%$, respectively.

\section{Results}

There are three SNPs that tag the three different LD blocks that exist in HSPDI (without containing the other genes, rs2340690, rs788016 and rs2605039). In a recent largescale genome-wide association study in the British population, one of them (rs788016) and one SNP in LD with rs2605039 (rs8539) were tested without significant results being obtained (Wellcome Trust Case Control Consortium 2007). As we performed a different approach (familybased) in a different population (French Caucasian), we tested these three SNPs. The observed genotype 
frequencies were in accordance with the HWE in controls. We observed a trend for overtransmission of the $C$ allele with the $C / C$ genotype significantly more frequent in cases than in controls for $\mathrm{rs} 2340690(P=0.04$, Table 2$)$. This association led to a replication test in sample 2 with the hypothesis of a $C / C$ genotype association with RA. This finding was not confirmed, and the allelic frequencies were nearly identical between cases and controls. The combined analysis of the two clinically identical samples (200 families) did not yield a significant result (Table 2).

Neither significant association nor linkage to RA was found for rs788016 and rs2605039 (Table 3), in agreement with the British study (Wellcome Trust Case Control Consortium 2007). The absence of linkage disequilibrium (LD) between the three SNPs was confirmed, and the results of the haplotype TDT analysis were not significant (data not shown).

When stratifying the sample for families with index presenting at least one PTPN22-620W allele or the HLA$D R B 1$ allele shared epitope status, no correlation with the HSPD1 genotypes was observed (data not shown).

\section{Discussion}

We studied HSPD1, a positional and functional RA candidate gene, since we hypothesized that it is a major

Table 2 Affected family-based controls (AFBAC), transmission disequilibrium test (TDT), and genotype relative risk (GRR) analyses for $\operatorname{rs} 2340690$

\begin{tabular}{|c|c|c|c|c|c|c|}
\hline \multirow[t]{2}{*}{ Allele and sample } & \multicolumn{3}{|c|}{ AFBAC } & \multicolumn{3}{|l|}{ TDT } \\
\hline & Cases & Controls & $P$ & $\%$ of trans & $n$ & $P$ \\
\hline$C$, sample 1 & 0.24 & 0.17 & 0.09 & 60 & 65 & 0.1 \\
\hline$C$, sample 2 & 0.21 & 0.20 & 0.7 & 52.3 & 63 & 0.7 \\
\hline$C$, sample $1+2$ & 0.23 & 0.18 & 0.14 & 56.2 & 128 & 0.15 \\
\hline
\end{tabular}

\section{GRR sample 1}

$\begin{array}{rrrr}C / C & 7 & 3 & 0.04(C / C \text { vs. others }) \\ C / T & 32 & 27 & \\ T / T & 55 & 64 & \end{array}$

GRR sample 2

$\begin{array}{rrrr}C / C & 3 & 2 & 0.9(C / C \text { vs. others }) \\ C / T & 34 & 33 & \\ T / T & 55 & 57 & \end{array}$

GRR Sample $1+2$

$\begin{array}{rrrr}C / C & 10 & 5 & 0.2(C / C \text { vs. others }) \\ C / T & 66 & 60 & \\ T / T & 110 & 121 & \end{array}$

$n$ is the number of heterozygous parents
Table 3 AFBAC, TDT and GRR analyses for rs788016 and rs2605039

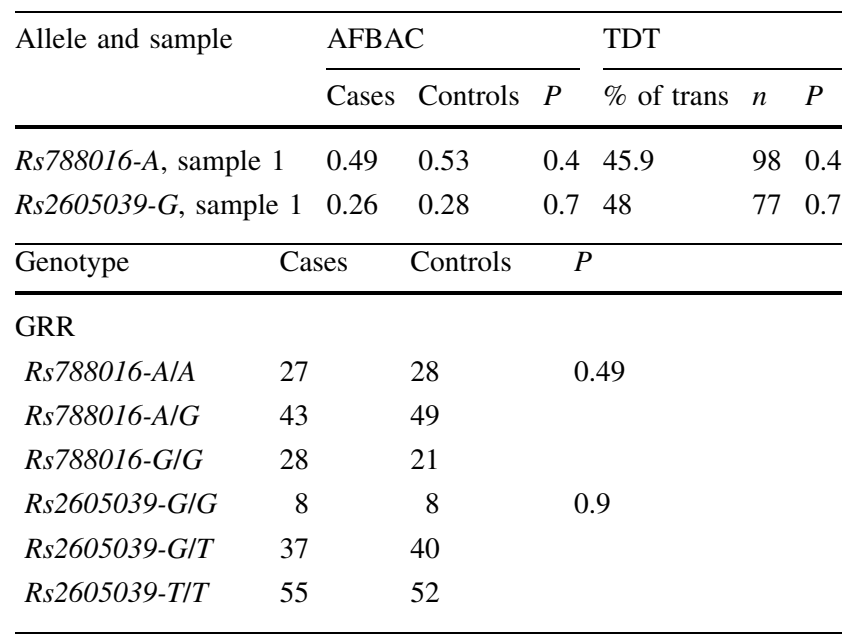

$n$ is the number of heterozygous parents

susceptibility gene by analyzing families from the French Caucasian population. We observed a significant RA association of the $C / C$ genotype for rs 2340690 in the first sample, which was not replicated in the second sample.

These results exclude the $r s 2340690-C$ allele from being a major RA genetic factor, but they cannot totally exclude a minor association. However, it would require 550 trio families with $80 \%$ detection power $(P<0.05)$ to find this association, and several thousands to confirm a definitive association $\left(P<10^{-6}\right)$.

To test our hypothesis, we studied the three tag SNPs corresponding to our criteria. Thus, we cannot totally exclude the notion that a very minor RA susceptibility allele exists in HSPDI.

This $2 \mathrm{q} 3$ susceptibility locus contains 101 genes (68 known) including one recently suggested susceptibility gene (Remmers et al. 2007, http://www.ensembl.org/ index.html). It seems very unlikely that HSPDI is involved in this susceptibility locus.

In conclusion, this study provides evidence that HSPDI is not a major RA susceptibility gene in the French Caucasian population.

Acknowledgments We thank the families and the following associations: Française-Polyarthritiques, Recherche-Polyarthrite, Polyarctique, Rhumatisme-Travail. Société Française Rhumatologie, Genopole, Université Evry, Shering-Plough, Pfizer, Amgen, Conseil Régional IDF, Conseil Général Essonne, Ministère Recherche-Enseignement Supérieur, Fondation Recherche Médicale, Hôpital Sud Francilien (France), Foundation Sciences-Technology (Portugal).

\section{References}

Arnett FC, Edworthy SM, Bloch DA (1988) The American Rheumatism Association 1987 revised criteria for the classification of rheumatoid arthritis. Arthritis Rheum 31:315-324 
Botstein D, White RL, Skolnick M (1980) Construction of a genetic linkage map in man using restriction fragment length polymorphisms. Am J Hum Genet 32:314-331

Cappello F, Tripodo C, Farina F (2004) HSP10 selective preference for myeloid and megakaryocytic precursors in normal human bone marrow. Eur J Histochem 48:261-265

Corydon TJ, Hansen J, Bross P (2005) Down-regulation of Hsp60 expression by RNAi impairs folding of medium-chain acyl-CoA dehydrogenase wild-type and disease-associated proteins. Mol Genet Metab 85:260-270

Garnier S, Dieudé P, Michou L (2006) The systemic lupus erythematosus new genetic factor IRF5 rs2004640-T allele is not linked to, nor associated with rheumatoid arthritis, in a family-based study from the French Caucasian population. Ann Rheum Dis 66:828-831

Jamin C, Dugue C, Alard JE (2005) Induction of endothelial cell apoptosis by the binding of anti-endothelial cell antibodies to Hsp60 in vasculitis-associated systemic autoimmune diseases. Arthritis Rheum 52:4028-4038

Lathrop GM (1983) Estimating genotype relative risks. Tissue Antigens 22:160-162

Michou L, Lasbleiz S, Rat AC et al. (2007) Linkage proof for PTPN22, a rheumatoid arthritis susceptibility gene and a human autoimmunity gene. Proc Natl Acad Sci USA 104:1649-1654

Osorio J, Bukulmez H, Petit-Teixeira E (2004) Dense genome-wide linkage analysis of rheumatoid arthritis including covariates. Arthritis Rheum 50:2757-2765

Perezgasga L, Segovia L, Zurita M (1999) Molecular characterization of the $5^{\prime}$ control region and of two lethal alleles affecting the hsp60 gene in Drosophila melanogaster. FEBS Lett 456:269273

Quintana FJ, Carmi P, Mor F (2003) DNA fragments of the human 60-kDa heat shock protein (HSP60) vaccinate against adjuvant arthritis: identification of a regulatory HSP60 peptide. J Immunol 171:3533-3541

Remmers EF, Plenge RM, Lee AT et al. (2007) STAT4 and the risk of rheumatoid arthritis and systemic lupus erythematosus. N Engl J Med 357:977-986

Sambrook P, Fritsch E, Maniatis T (1989) A laboratory manual, vol 1, 2nd edn. Cold Spring Harbor Laboratory Press, New York

Seldin MF, Amos CI, Ward R (1999) The genetics revolution and the assault on rheumatoid arthritis. Arthritis Rheum 42:1071-1079

Spielman RS, McGinnis RE, Ewens WJ (1993) Transmission test for linkage disequilibrium: the insulin gene region and insulindependent diabetes mellitus. Am J Hum Genet 52:506-516

Tezenas du Montcel S, Michou L, Petit-Teixeira E et al. (2005) New classification of HLA-DRB1 alleles supports the shared epitope hypothesis of rheumatoid arthritis susceptibility. Arthritis Rheum 52:1063-1068

Thomson G (1995) Mapping disease genes: family-based association studies. Am J Hum Genet 57:487-498

Wellcome Trust Case Control Consortium (2007) Genome-wide association study of 14,000 cases of seven common diseases and 3,000 shared controls. Nature 447:645-646

Zanin-Zhorov A, Cahalon L, Tal G (2006) Heat shock protein 60 enhances CD4+ CD25+ regulatory $\mathrm{T}$ cell function via innate TLR2 signaling. J Clin Invest 116:2022-2032 